\title{
An Integrative Approach to Developing Social Justice Leadership by Enhancing Body Awareness, Mindfulness and Transformational Styles of Interaction
}

\author{
Mary Margaret Fonow, PhD ${ }^{1 *}$, Judith A. Cook, PhD ${ }^{2}$, Jane Burke-Miller, PhD ${ }^{3}$, Richard Goldsand ${ }^{4}$ \\ ${ }^{I}$ Norton and Ramsey Emerita Professor of Social Transformation School of Social TransformationArizona State \\ University Wilson Hall, 240 Orange Mall Tempe, Arizona, 85281 \\ ${ }^{2}$ Professor and Director Center on Mental Health Services, Research and Policy Department of Psychiatry \\ University of Illinois at Chicago 1601 W. Taylor Street, 4th Floor, M-C912 Chicago, IL 60612 \\ ${ }^{3}$ Center on Mental Health Services, Research and Policy Department of Psychiatry University of Illinois at Chicago \\ 1601 W. Taylor Street, 4th Floor, M-C912 Chicago, IL 60612 \\ ${ }^{4}$ School of Social Transformation Arizona State University Wilson Hall, 240 Orange Mall Tempe, Arizona, 85281
}

*Corresponding Author:Mary Margaret Fonow, Norton and Ramsey Emerita Professor of Social Transformation School of Social Transformation Arizona State University Wilson Hall, 240 Orange Mall Tempe, Arizona, 85281

\begin{abstract}
We used a multi-dimensional pedagogical approach to developing leadership for social justice through a graduate level academic course entitled Social Transformation and Embodied Activism, which combined didactic instruction, somatic education, reflexive journaling, and mindfulness practices. Subjects were 14 college students who participated in 16, weekly 2.5-hour classes, and completed research assessments at the beginning, mid-point, and end of the semester. Outcome measures included body awareness, mindful attention, and transformational leadership style. Results indicated significant increases on each of the three outcomes between T1 and T2 and between T1 and T3 in unadjusted paired t-tests. These increases persisted in longitudinal generalized estimating equations controlling for age, gender, and racelethnic group. Qualitative analysis of students' journals, meditation logs, and reflexive essays revealed how different class components affected their somatic perceptions, self-awareness, and attitudes toward leadership. Our findings suggest that students exposed to multiple pedagogical techniques that engaged their minds, bodies, and emotions experienced significant increases in capacities thought to enhance leadership for social transformation.

Keywords:transformational leadership, embodied activism, mindfulness, body awareness, social justice, pedagogy, somatic practice
\end{abstract}

\section{INTRODUCTION}

Increasingly, educators and activists in the field of social justice have used contemplative practices, such as mindfulness and somatic education, to prepare emerging leaders for the challenges of transformational leadership and social activism. Mindfulness practices facilitate the integration of mind, body, and emotions, including methods such as meditation, reflection, and visualization. Somatic education uses sensory motor learning to acquire greater voluntary awareness and control over the movement of one's body through the environment (Eddy 2009). Research suggests that mindfulness and somatic education help leaders remain in the present by better managing their own emotional responses to change and staying focused on the vision and goals of an organization or movement (Brendel and Bennett 2016; Cantrick et. al 2018; Ergas 2013; Pitts-Taylor 2016; Rockefeller 2006). The aim of this study was to explore the use of an interrelated set of pedagogical practices in a college curriculum designed to prepare students for social justice activism by integrating embodied leadership training, somatic education, and mindfulness. 
An Integrative Approach to Developing Social Justice Leadership by Enhancing Body Awareness, Mindfulness and Transformational Styles of Interaction

The impetus for developing a course on transformational leadership and embodied activism came from the desire to help students develop practical leadership skills for social justice work by concentrating on the activist as a whole person. The context for development of this pedagogical approach is the School of Social Transformation (SST) at Arizona State University. SST is a transdisciplinary academic unit with an instructional staff of 54, teaching over 12,000 students per year including 800 students pursuing degrees and certificates in graduate and undergraduate programs of study including African and African American Studies,Asian Pacific American Studies, Justice and Social Inquiry, Social and Cultural Pedagogy, American Studies, and Women and Gender Studies. The school offers certificates in Human Rights, Sexuality Studies, Economic Justice, Socio-legal Studies, and Social Transformation, and houses three research centers including the Center for Indian Education, the Center for Work and Democracy and the Center for Gender Equity in Science and Technology.

SST offers students opportunities to study the complexity of diversity and social justice while learning about the historical, cultural, and social forces that shape U.S. society. They not only study systems of oppression, discrimination, and inequality, but the social, cultural, and political struggles for social change such systems engender-nationally and transnationally. The majority of SST students (52\%) are students of color, $75 \%$ are female, and $41 \%$ are first generational college students. Students bring to the classroom valuable first-hand knowledge about these unjust systems and how to challenge them but are less aware of how they embody these struggles and how they might tap into the body as a source of knowledge that can help to sustain their activism in difficult and uncertain times. Our graduates find careers in socialjustice organizations, equity and anti-oppression initiatives, diversity programs, schools and universities, nonprofit organizations, labor unions, social movement organizations, and advocacy agencies serving communities harmed by complex, intersecting structures of oppression and inequality. The School of Social Transformation is an ideal site to develop and evaluate our holistic pedagogy for social justiceleadership.

Our work responds to a call for models of social movement leadership training that move away from sole reliance on developing standardized skills and cognitive competencies toward a more holistic approach that emphasizes leadership for liberation and social justice (Cantrick et al. 2018; Conners and Poutianne 2010; Johnson 2018; Magee 2017). Transformational leadership requires the ability to inspire action, stimulate new thinking, adapt to different contexts, and consider individual differences (Kuepers 2011; Kuhnert and Lewis 1987). In this style of leadership, the line between leader and follower is often blurred, with each reciprocally influencing the other and even exchanging roles, depending on the situation (Burns 1978). Pinck and Sonnentag (2018) found that transformational leadership plays a mediating role between leaders' and employees' well-being because mindfulness enhancesthe qualities and skills characteristic of transformational leadership.

According to Kuepers (2011), embodiment is an important element of social justice leadership. Bodies and bodily performances-including physical stature, features, stance, gestures, and voice-are central, yet ignored, elements in the enactment of leadership (Ladkin 2008; Sinclair 2005). Body-awareness provides the individual with opportunities to connect bodily sensations to affective states and thereby better manage negative emotions. The ability to regulate emotions and not be reactive is critical for staying in the present. Staying in the present allows leaders to listen to others, find flexible solutions, and behave in ways that are congruent with their ideals, values, and purpose (Glomb 2011). Brendel and Bennett (2016) argue for an embodied leadership training model where leaders with greater awareness are able to process real-time insights and reflexively examine these insights to formulate an authentic capacity that is more closely aligned with the competing demands of social relations. They argue that through somatic practices, embodied leadership can be enacted in ways that allow leaders to better align presence and purpose, and in ways that followers view as open, engaged, andtrustworthy.In their meta-analysis of Mindfulness Based Programs (MBP) in work settings Vonderlin et al. (2020), found that these programs positively affect the health and well-being of employees and improve workplace functioning by increasing self-regulation of attention to the present and reducing stress, thus increasing employee 
An Integrative Approach to Developing Social Justice Leadership by Enhancing Body Awareness, Mindfulness and Transformational Styles of Interaction

engagement, productivity and job satisfaction. Our approach is unique in seeking to promote effective social justice activism by employing the evidence-based somatic education method of Feldenkrais to teach students what it means to be an embodied leader in contentious situations that characterize social and political activism. Feldenkrais is a method of somatic education that uses guided exercises to make individuals aware of their habitual neuromuscular patterns and rigidities and teaches participants new ways of moving that increase sensitivity and improve bodily efficiency (Reese, 2015).

Research has shown that it improves self-rated health, reduces perceived stress, and enhances body awareness among people with diverse disorders such as chronic pain (Ohmann et al. 2011), musculoskeletal disorders (Malmgren-Olsson et al. 2001), multiple sclerosis (Johnson et al.1999), and stress-related illnesses (Heiden et al. 2007). A growing body of neuroscienceresearch has identified a network of brain regions where interoception, or the focusing of attention on internal body sensations, is related to emotions and decision making involved in social justice work (Farb et al. 2015; Farmer and Maister 2017; Jost et al. 2014; Niemi and Young 2017). We have previously published two studies on the use of Feldenkrais Awareness through Movement to enhance interoception. In one study, we found that students enrolled in a Feldenkrais course experienced an increase in mindfulness, body awareness, and empathetic leadership (Fonow et al., 2017a). In another study, we found that a one-session Feldenkrais workshop increased mindfulness, enhanced body awareness, and reduced stress (Fonow et al., 2017b).

In addition to Feldenkrais, our approach uses mindfulness practices such as meditation, visualization, and journaling to slow actors' cognitive thought processes, allowing them to develop empathy and see the world from the perspective of others. Cognitive deceleration also promotes detachment, which allows people to relinquish control and forgo the impulse to be judgmental. We also use role-playing in simulated situations of social activism such as protests, demonstrations, and negotiations, to help students integrate these new strategies in "real time." In the current study, we investigate whether all of the components of our pedagogy (mindfulness, simulations, writing prompts, Feldenkrais) work together to enhance multiple capacities involved in effective leadership for social change.

\section{METHOD}

\subsection{Participants}

Participants were 14 graduate students in a course on transformational leadership and embodied activism who agreed to provide data for this study. All participants were enrolled in a graduate program at ASU. Participants were mostly female $(n=11$ or $79 \%)$. Half were White $(n=7,50 \%)$, followed by African American $(n=4,29 \%)$, Latinx $(n=2,14 \%)$, and Native American $(n=1,7 \%)$. Ages ranged from 20 to 50 years, with an average age of 26 years(standard deviation=8).

\subsection{Procedures}

At the first course session, one of the instructors described the purpose of the study, what study participation would involve, risks and benefits, and participant protections. Students were told that study participation was voluntary and separate from their coursework, that they could remain in the course if they chose not to participate in the research, that research participation would not affect their course grade or relationship with the instructors, and that they could elect to skip any assessments or questionnaire items they wished. The instructor then left the classroom and a professor who was not one of the instructors answered questions about the study and obtained written informed consent. While all 17 enrolled students agreed to participate, one subsequently withdrew from the study, and 2 others did not submit complete data. All human subjects research procedures were approved by the ASU Institutional Review Board.

Following the informed consent process, the pre-test was completed, and the intervention began immediately. At the eighthclass session, mid-point assessments were completed. After the final eight sessions, the post-test was administered. Pre-, mid-point, and post-tests consisted of paper-and-pencil self-report assessments, described below. With students' permission, qualitative data were collected from weekly journals, meditation logs, and their final reflective essays, as described below. 
An Integrative Approach to Developing Social Justice Leadership by Enhancing Body Awareness, Mindfulness and Transformational Styles of Interaction

\subsection{Intervention}

The intervention consisted of 16, 2.5-hour weekly sessions. At each session, students engaged in a discussion of assigned readings from academic journals on topics related to different domains of social justice (e.g., gender, labor, environment, immigration, race, sexuality, and disability) and transformational leadership. In conjunction with these discussions, students engaged in role-playing via structured simulations designed to reflect article content. Students then participated in a 40-minute Feldenkrais Awareness through Movement (ATM) lesson led by a certified Feldenkrais practitioner. Each ATM session began with a brief presentation on the work of Moshe Feldenkrais and related neuroscience literature, followed by bodywork on four topics: coordinating Flexor/extensor muscles; breathing awareness and control; spatial orientation; and eye and hand movement. By lying on the floor at the beginning and end of each session for a "body scan," students learned which parts of the body held tension and which were less tense at the end of the session. Flexor/extensor lessons helped students discern how they might be taxing these muscles and ways to move more naturally, thereby reducing unnecessary muscle contractions. Next students learned to identify their habitual ways of breathing and how breathing is connected to routine functions such as talking, sitting, and standing. Lessons concerning spatial orientation acquainted students with movement options that allowed for a more even distribution of effort across the body. Eye and hand lessons illustrated how information overload occurs when excessive stimuli are encountered visually and tactilely, and how small movements of the hand and eye could reduce strain. After the ATM session, forthefinal segment of the class, students participated in a 10minute guided meditation session led by one of the instructors.

Between class sessions, students were assigned to meditate daily and keep a log of the number of minutes they meditated and any insights they gained. They also were assigned to keep a weekly journal in which they recorded observations regarding the previous week's readings and ATM lesson. In addition, between sessions, they were asked to post their thoughts about each week's readings and activities to the class Blackboard site that was accessible to all students and the professors. Finally, students were required to prepare a reflexive essay applying the concept of transformational leadership and embodied activism to their own work as leaders oractivists.

Course materials included books, articles, videos, and podcasts covering a wide range of social justice issues and embodied forms of learning. We drew extensively on materials provided by the Haas Institute for Othering and Belonging at the University of California and the Center for Mindfulness, Compassion, and Resilience at Arizona State University.

\subsection{Measures}

The Body Awareness Scale (BA) measures the ability to recognize subtle internal body cues and includes 12 items scored from 0-4 $(0=$ not at all to $4=$ all the time $)$, and averaged, with higher scores indicating more body awareness. Sample items include: "When I am tense, I take notice of where the tension is located in my body" and "I listen for information from my body about my emotional state." Total mean score was computed with no assessments missing more than one item. Cronbach's alphas showed good internal reliability at each time point: $\mathrm{T} 1=.83, \mathrm{~T} 2=.90, \mathrm{~T} 3=.78$.

The Mindful Attention Awareness Scale (MA) (Brown and Ryan 2003) is designed to assess a receptive state of mind in which attention is paid to what is occurring in the present.Sample items include "I find it difficult to stay focused on what's happening in the present" and "I tend to walk quickly to get where I'm going without paying much to what I experience along the way." It has been validated for use with college students and adults (Brown and Ryan 2003). For the present study, 8 items were included and scored from 1-6 $(6=$ almost always to $1=$ almost never $)$, and averaged, with higher scores indicating more mindfulness. Cronbach's alphas showed good internal reliability at each time point: T1=.65, $\mathrm{T} 2=.74, \mathrm{~T} 3=.76$. 
Transformational Leadership Style (TLS) was defined as engaging followers to think in new ways, treating people as individuals, and encouraging followers to achieve levels of performance beyond their expectations. It was assessed using a subscale of the Multifactor Leadership Questionnaire (MLQ) (Avolio and Bass 1995) consisting of 20 items scored 0-4 $(0=$ Not at all to $4=$ Frequently if not always). Sample items include "I consider the moral and ethical consequences of decisions" and "I consider an individual as having different needs, abilities, and aspirations from others." Items were averaged, with higher scores representing greater transformational leadership style. Cronbach's alphas showed good internal reliability at each time point: $\mathrm{T} 1=.78, \mathrm{~T} 2=.76, \mathrm{~T} 3=.81$.

\subsection{Analysis}

We examined changes in body awareness, mindful attention, and transformational leadership style between $\mathrm{T} 1$ and $\mathrm{T} 2$, and between $\mathrm{T} 1$ and $\mathrm{T} 3$ using paired t-tests. We next examined changes over time while adjusting for demographic characteristics using Generalized Estimating Equations (GEE). We modeled time as a factor in the GEE in order to compare differences between T1 and T2, and T1 and T3. We used the constant comparative method (Glaser and Strauss 1966) to analyze students' qualitative accounts in meditation logs, journals, Blackboard discussion posts, and a final essay.

\section{RESULTS}

Quantitative results.As shown in Figure 1, mean scores on Body Awareness, Mindful Attention, and Transformational Leadership Style increased over the 3 study time points. Most of the positive change was between T1 and T2, with slight declines after T2. Body awareness increased from a mean (SD) of 2.3 (0.6) at T1 to $3.2(0.5)$ at T2 and $2.9(0.5)$ at T3. Mindful Attention increased from a mean (SD) of 3.0 $(0.8)$ at $\mathrm{T} 1$ to $3.8(0.7)$ at T2 and $3.7(0.7)$ atT3.Transformational Leadership Style increased from a mean $(\mathrm{SD})$ of $3.0(0.4)$ at $\mathrm{T} 1$ to $3.3(0.3)$ at $\mathrm{T} 2$ and $3.2(0.4)$ at $\mathrm{T} 3$.

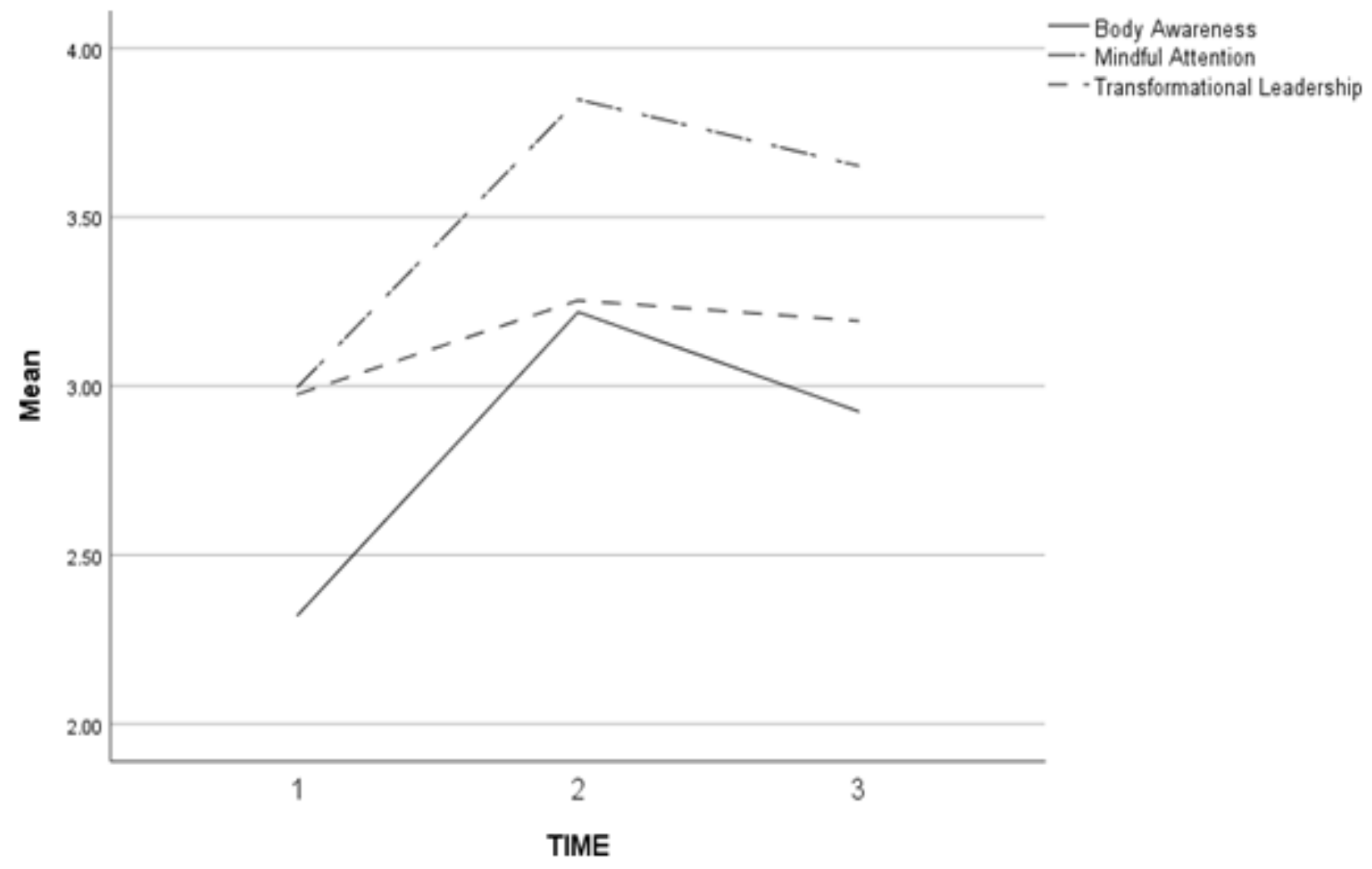

Figure1.Body Awareness, Mindful Attention and Transformational Leadership Style over time 
An Integrative Approach to Developing Social Justice Leadership by Enhancing Body Awareness, Mindfulness and Transformational Styles of Interaction

Table 1 shows the results of paired t-tests indicating significant increases in body awareness between $\mathrm{T} 1$ and T2 ( $\mathrm{p}<.001)$ and T1 and T3 (p=.003). Also significant between T1 and T2, and between T2 and T3 were increases in Mindful Attention ( $\mathrm{p}<.001$ and $\mathrm{p}=.003$, respectively), and Transformational Leadership Style ( $\mathrm{p}=.014$ and $\mathrm{p}=.037$, respectively).

Table1.Descriptive measures of Body Awareness, Mindful Attention Awareness Scale, and Transformational Leadership Style at 3 time points. Paired t-tests compare mean differences between T1 and T2, and T1 and T3. $N=14$.

\begin{tabular}{|c|c|c|c|c|c|c|c|c|c|c|c|}
\hline & \multicolumn{3}{|c|}{ Time 1} & \multicolumn{3}{|c|}{ Time 2} & \multicolumn{3}{|c|}{ Time 3} & \multicolumn{2}{|c|}{$\begin{array}{l}\text { Paired t-tests (2- } \\
\text { tailed, d.f.=13) }\end{array}$} \\
\hline & Mean (SD) & $\begin{array}{l}\text { Min- } \\
\text { Max }\end{array}$ & Median & $\begin{array}{l}\text { Mean } \\
(\mathrm{SD})\end{array}$ & $\begin{array}{l}\text { Min- } \\
\text { Max }\end{array}$ & Median & $\begin{array}{l}\text { Mean } \\
\text { (SD) }\end{array}$ & $\begin{array}{l}\text { Min- } \\
\text { Max }\end{array}$ & Median & T1-T2 & T1-T3 \\
\hline $\begin{array}{c}\text { Body } \\
\text { Awareness }\end{array}$ & $2.3(0.6)$ & $1.4-3.3$ & 2.3 & $3.2(0.5)$ & $2.3-4.0$ & 3.2 & $2.9(0.5)$ & $2.1-3.6$ & 3.0 & $\begin{array}{l}\mathrm{t}=5.9 \\
\mathrm{p}<.001\end{array}$ & $\begin{aligned} \mathrm{t} & =3.7 \\
\mathrm{p} & =.003\end{aligned}$ \\
\hline $\begin{array}{c}\text { Mindful } \\
\text { Attention } \\
\text { Awareness } \\
\text { Scale }\end{array}$ & $3.0(0.8)$ & $1.9-4.7$ & 2.9 & $3.8(0.7)$ & $2.4-4.9$ & 3.9 & $3.7(0.7)$ & $2.1-4.8$ & 3.7 & $\begin{array}{c}t=5.6 \\
p<.001\end{array}$ & $\begin{array}{c}\mathrm{t}=3.7 \\
\mathrm{p}=.003\end{array}$ \\
\hline $\begin{array}{l}\text { Transforma- } \\
\text { tional } \\
\text { Leadership } \\
\text { Style }\end{array}$ & $3.0(0.4)$ & $2.4-3.9$ & 3.0 & $3.3(0.3)$ & $2.7-3.8$ & 3.2 & $3.2(0.4)$ & $2.6-3.7$ & 3.1 & $\begin{array}{c}\mathrm{t}=2.9 \\
\mathrm{p}=.014\end{array}$ & $\begin{array}{c}\mathrm{t}=2.3, \\
\mathrm{p}=.037\end{array}$ \\
\hline
\end{tabular}

Min-Max=minimum-maximum

Table 2 presents the results of longitudinal generalized estimating equations (GEE) controlling for age (10-year increments), gender (male vs. female), and race/ethnic group (people of color vs. white). Changes in outcome measures over time were positive and significant, even controlling for participant demographic characteristics. GEE analysis found no significant relationships between demographic characteristics and the two outcomes of body awareness and transformational leadership. In the model predicting mindful attention, males and older students showed significantly greater increases in mindful attention than females and younger students $(\mathrm{p}=.001$ and $\mathrm{p}=.006$, respectively).

Table2.Change in Body Awareness, Mindful Attention Awareness Scale, and Transformational Leadership Style measures over time adjusting for demographic characteristics: Generalized Estimating Models (GEE) (n=14 individuals and 42 observations).

\begin{tabular}{|c|c|c|c|c|c|c|}
\hline & \multicolumn{2}{|c|}{ Body Awaress } & \multicolumn{2}{c|}{ Mindful Attention } & \multicolumn{2}{c|}{ Transformational LeadershipStyle } \\
\hline & Est (SE) & p-value & Est (SE) & p-value & Est (SE) & p-value \\
\hline Time & & & & & & \\
Time 2 vs. Time1 & $0.90(0.14)$ & $<.001$ & $0.85(0.15)$ & $<.001$ & $0.28(0.09)$ & .003 \\
Time 3 vs. Time1 & $0.60(0.16)$ & $<.001$ & $0.65(0.17)$ & $<.001$ & $0.22(0.09)$ & .016 \\
\hline Gender (male vs. female) & $-0.18(0.21)$ & .404 & $0.82(0.24)$ & .001 & $0.32(0.21)$ & .126 \\
\hline Race group (People of & $0.27(0.20)$ & .190 & $-0.09(0.20)$ & .668 & $0.19(0.12)$ & .127 \\
Colorvs. White) & & & & & & $-0.03(0.06)$ \\
\hline Age, 10 year increments & $-0.10(0.1)$ & .369 & $0.38(0.14)$ & .006 & & .622 \\
\hline
\end{tabular}

Qualitative results. Through their meditation logs, journals, Blackboard posts, andfinalessays, students described and reflected upon the ways in which the course influenced their body awareness, mindfulness, and leadership conceptions and activities. Students report greaterbodyawareness after the Feldenkrais lesson and are able to link bodily sensations to feeling states and cognition. One student described how his increased awareness of his body's range of motion had led to a more expansive way of thinking: 
Today's Feldenkrais lesson involved restraint in certain movements. In one, I had to leave one arm pinned to the floor. In another, both arms worked together albeit in opposite directions. I actually, physically, experienced a broader range of movement in my neck. If there is a way I can implement this same kind of dynamic, it might be possible to move away from the oppositional thinking I usually resort to. (MAR-892, journal entry)

Another student described an insight in which she connected a physical habit of tensing her shoulders with feelings of defensiveness.

I am building the habit of when I feel defensive or tense, taking time to notice how my body feels in these moments. I have found that my shoulders tense up when I'm starting to feel defensive. I am taking time to relax my body before proceeding. (BET240, journal)

A third student reported that a Feldenkrais lesson on coordinating flexor/extensor muscles left her feeling more grounded and present.

The standing Feldenkrais lesson was interesting. I felt vaguely unsettled and unbalanced throughout, and found I had to keep my eyes open. Since starting the class, I've been noticing the feeling of being grounded more. I derive comfort from having my feet flat on the ground and simply focusing on the weight and pressure. It makes me feel morepresent and connected to the world around me. (MAR-901, journal)

Students also described changes related to enhanced mindfulness. An African American man described an insight he developed from meditation:

Mindful reflections allow me to acknowledge my own advantaged statuses, since I traditionally focus on the ways in which I am disadvantaged. Recognition of my own privilege...will allow me to work alongside groups who are being marginalized [and avoid] the trap of believing that certain social issues are not my fight. (MR-919, meditation log)

Another respondent took her newfound mindfulness practices home with her and reflected on its effect on her family.

My household is starting to add meditation to our daily routine... We noticed a difference in all of our attitudes. We were positive throughout the day, less tired, and managed stress more effectively. (TAM-915, journal)

Yet another woman described how she used mindfulness skills to re-examine tense interactions: "I reflect upon my reactions after the fact". Through this reflection, I have made it a habit to acknowledge the path I took, and how I could have handled the situation differently, which will influence my actions in the future. (BET-240, finalessay)

Students also provided examples of how what they learned in the class had affected their views of themselves as leaders, advocates and change agents. One student, a member of the professional staff at the university with supervisory responsibilities, described how her leadership style had changed as a result of the course:

I was thinking about how my leadership skills have been evolving since the beginning of class. Being more aware of my body, breathing, emotions, and reactions have helped me develop what I like to call the leadership dance. [By this I mean] how I have been fluid asI assume a role depending on the situation or work I am involved in...I can think more clearly. I am willing to listen to others and take their views into account. (DAN-570, journal) 
An Integrative Approach to Developing Social Justice Leadership by Enhancing Body Awareness, Mindfulness and Transformational Styles of Interaction

Another student wrote of how embodied activism could be helpful for educating Native populations, including her own indigenous tribal group:

Embodied activism is not something that can be turned on and off. It means that I understand my body and mind together, and then understand how my actions relate to the world. In doing this, I hope to push transformation in education, specifically for indigenous people. (TAM-915, final essay)

Some students become more aware of the toll activism can take on the body and how the tools we provided in the course helped them to remain true to their intentions despite opposition. One student described the following:

Banding together and demanding better conditions is an act of courage and one which can be emotionally and physically draining. Mindfulness practices can help activists find and retain their inner purpose and sense of self and dignity despite the opposition they face. (MAR-901, journal)

Some students noted their increased awareness of the importance of perspective-taking and empathy in social justice activism. For example, one student's final essay described how the course had helped her gain a deeper connection to her ancestors and a better sense of their struggles:

I believe that a deeper understanding of myself and an embodied way of life allows me to have empathy for my Native American ancestors in a way that allows me to continue their resistance to cultural oppression. (TAM-915)

Another student who was reluctant to identify as an activist at the beginning of the course described how her view of activism had changed by the end of the term:

I now realize that being an activist is not just being at the endpoint of a change process, but also playing a part in influencing others and demonstrating an alternative approach toward reality. So now I begin to understand that I can define myself as an activist. In this course I gained knowledge, skills and practices for my own life and to pass on to my students and others. (OMR-626, final essay)

Students also described how the required readings helped them to develop a deeper and more nuanced understanding of transformational leadership and embodied activism. One student described this as follows:

I loved the discussion board questions for the readings this week where we were asked to consider how self-reflection helps us to create new ways of being and acting that better align with the vision and values of social transformation. Many do not recognize the unconscious ways that certain "multiple forces" shape our experiences and values which makes it so difficult to feed change,...I think that in any work, selfreflection and self-reflexivity should be a huge part of transformative and leadership, where we do not fall into the dangerous (and habitual) cycle of oppositional resistance. (ZEW-885, discussion board).

Another student, a white cisgender straight woman, discussed feeling paralyzed about how to be an activist given that she had experienced so much privilege in her life. She described her reservations about even signing up for a course on activism, "the activism piece almost made me want to shy away. I was unsure about my role in the struggle for positive social change, or if I even deserved to play one." However, by the end of the term, she had gained a more complex understanding of activism, and felt more comfortable positioning herself in an egalitarian, supportive form of social change. 
"Over the course of this class, I witnessed a growth and change in the depth of our conversations and the relationships formed. People were willing and enthusiastic to participate, and we were open to the many different discussion and teaching techniques employed. When we participated in an activism simulation that many were not prepared for and it left some folks hurt or upset, other classmates came to their aid and suggested ways we could do better. For the most part after that class, we did do better and this was not by chance. (AMY-399 journal entry)

Finally, some students recognized the value of embodied activism for staying in the present when engaging in coalition building. One student wrote in her final essay:

Activism requires a certain attention to the present that sometimes makes it feel impossible to attend to both material bodies and metaphysical commitments simultaneously, but it is crucial to forming strong, meaningful collations. Recognizing the unique, situated knowledge of each member of a coalition-not simply each essentialized identity is imperative (MON-021, final essay).

\section{DisCUSSION}

Our quantitative and qualitative results suggest that students were able to use the somatic education through Feldenkrais to become more aware of their bodies and the connection of their bodies to their emotional states. Many also described success at being able to change their bodies/breathing/seeing and emotional reactions to a healthier or more desirable state. In particular, students made connections between body awareness, thoughts, and emotions and how they could connect bodily sensations to doing things differently, thus changing unhelpful habits. They commented on an increased ability to remain in the present, stay grounded, expand options, and respond with less reactivity. They connected greater freedom in movement to greater freedom in thinking.

Not all students made the connection between their somatic learning and emotional reactions and application in leadership situations. To some extent, this could be due to the fact that not all had been in leadership positions and had leadership experience to draw on. Those who did have this experience seemed better able to make the connection between somatic, emotional, and cognitive options, in what one referred to as a "leadership dance." Another student described herself as an emergent leader in the field of disability studies and said she hoped to "lead from behind by using my privilege and position to construct new spaces for new kinds of expertise to flourish, I do not wish to occupy the spotlight, but to build the stage and gather the audience."

Over the course of the class, it was possible to see the progression of sophistication in students' understanding of key concepts such as embodied leadership, reactivity, being in the present and transformational styles of social activism. Common student observations regarding the readings included: 1) how social justice issues are interconnected; 2) how activist leadership training in other fields mirrored what they were learning from the class; 3) varieties of feminism and intersectionality; 4) how hard it is for activists when their local communities do not endorse their activist views; and 5) the value of learning to take the perspective of others.

In terms of potential changes to our pedagogical approach, we believe it would have been helpful to have more time at the beginning of each class for an extensive check-in that would allow the students to process what happened the previous week, to remind students of what was valuable in preceding classes, and to create a thread running throughout the term. Another potential change involves the addition of more simulations. Given lack of experience with leadership roles on the part of some students, it might be beneficial to make more use of role-play and simulated situations of common leadership dilemmas and scenarios of injustice in order to help students to make connections more apparent. One student noted that while the role-play we executed in class made her feel uncomfortable in the moment, it did however make her more aware of her body's visceral reaction to the scenario enacted. 
An Integrative Approach to Developing Social Justice Leadership by Enhancing Body Awareness, Mindfulness and Transformational Styles of Interaction

Our findings confirmed for us the value of integrating the three components of our pedagogy, Feldenkrais Awareness through Movement lessons, mindfulness activities, and meditation for transformational leadership training for social justice. From pre-to post-intervention, students showed significant improvement in body awareness, mindfulness, and self-perceived transformational leadership abilities. Significant improvements in body awareness and leadership capacities were found regardless of demographic characteristics. Regarding gender, pre- to post- changes in women and men were significant for all measured outcomes although men registered the largest increase in mindfulness. These results suggest that our holistic integrated approach holds promise for training both men and women for transformational leadership and social justice activism. Similarly, there were no racial difference suggesting that our pedagogy is useful for training leaders in mixed racegroups.

Findings also underscore important interconnections between body, mind, and emotions in preparing young people for transformational leadership roles. In the analysis of journals, meditation logs, discussion boards and final essay, we found evidence that students were developing the body awareness needed to stay grounded and in the present. They learned to associate bodily sensations with feeling states and emotions and learned how to interrupt habitual patterns of movement-a first step in regulating emotions. This awareness led to being less defensive about their own judgements and better able to take the perspective of others. Although the evidence is inconsistent, perspective taking has been linked to the reduction of prejudice and the increase of tolerance for people of different races and ethnicities.Individuals who score higher on measures of mindfulness rely less on automatic processing, (or what Feldenkrais calls the habitual), when interpreting the external environment (Adelheid, et. al 2018). Furthermore, interoception plays an important role in decision-making. According to Farb and colleagues (2015), two capacities, presence and agency, emerge when the embodied self is more fully realized through awareness of interoceptive processes. Both capacities are fundamental to social transformational leadership. We believe mindfulness and embodiment are a potent combination. Chari (2016) argues that embodiment is the key to articulating the political potential of mindfulness by deepening the capacities of relationality, empathy, and attunement. As a somatic practice, Feldenkrais can cultivate the type of mindful embodiment that can produce new forms of sociality and open new possibilities for bringing about a more just world. By becoming more aware of internal physical sensations, students may be able to read when their actions are not congruent with their goals and ideals and make adjustments in their behavior. Others may then perceive them as leaders with integrity and therefore see them as more trustworthy.Developing a leadership training program that helps participants translate thinking and feeling into action by connecting our internal states to our external behavior is foundational to social transformation. We need,as argued by Bhikkhu, (2020), to broaden the scope of mindfulness.

\subsection{Limitations}

Some caveats apply to our study findings. First, study participants were not nationally representative of college students since they were recruited from a single state university in the Southwest. Second, without a control group, we are unable to attribute the pre/post changes in body awareness, mindfulness and transformational leadership and stress that we observed to participation in the intervention itself. Third, the self-report nature of the measures we used may have introduced positive response biases from students wishing to portray themselves in a more "progressive" and "informed" light. Fourth, administering the post-test assessment immediately after the intervention did not allow participants additional time for changes in leadership, body awareness and other behaviors that might have been reflected in the attitudinal measures. While these limitations are not insignificant, our study is intended as an initial step in curriculum development that requires the demonstration of linkages between the components of our planned intervention. To ascertain whether we are heading in the right direction, establishing that these associations exist, even in a non-causal research design, is important to our next stage of intervention development. 
An Integrative Approach to Developing Social Justice Leadership by Enhancing Body Awareness, Mindfulness and Transformational Styles of Interaction

\section{CONClusion AND Future Directions}

We are living in a period where politics is driven by resentments, fear, and anger - the type of emotions that are not particularly conducive to building the coalitions and solidarities it will take to achieve social justice. We live in a world where bodies are entangled in systems of oppression and discrimination and where the struggles to resist are difficult, uncertain and hard to sustain. We join a growing list of scholars and interventionists calling for new forms of activism, particularly embodied forms that address the whole person in a healthy and sustaining fashion. We also suggest a series of challenges and dilemmas whose resolution is necessary in order to create these new conceptualizations of activism. How do we create social justice organizations that endure? How do we ensure that activists donot burn out or cause harm to each other? What new social relations and organizations are required to build sustainable social movements and how can mindful embodiment help us to envision new ways of being together in communities of action? How can we be more intentional in preparing students and others to be transformational leaders and followers? To answer such questions will require a more fully developed transformational leadership intervention, more rigorous research design and instrumentation, and measurement of outcomes by following students into the real world as they seek to promote social justice and societal change.

\section{REFERENCES}

[1] Adelheid,A.M., Nicol,M., and DeFrance, K. (2018). Mindfulness: relations with prejudice, social dominance orientation and right-wing authoritarianism. Mindfulness, 9, 1916-1930.

[2] Avolio,B.and Bass, B. (1995). Multifactor leadership questionnaire. American Psychological Association: APA PsycTests.

[3] Bhikkhu, A. (2020). Confronting racism with mindfulness. Mindfulness(in press)

[4] Brendel,W., and Bennett, C. (2016). Learning to embody leadership through mindfulness and somatic practices. Advances in Developing Human Resources, 18(3), 409-425.

[5] Brown,K.W. and Ryan, R.M. (2003). The benefits of being present: Mindfulness and its role in psychological well-being. Journal of Personality and Social Psychology, 84, 822-848.

[6] Burns,J. M. (1978). Leadership. New York. NY: Harper and Row Publishers.

[7] Cantrick,M., Anderson, T., Bennett Leighton, L. and Warning, M. (2018). Embodying activism: Reconciling injustice through dance/movement therapy. American Journal of Dance Therapy, 40, 191-201.

[8] Chari, A. (2016). The political potential of mindful embodiment. New Political Science.38(2), 226-240.

[9] Conners, D.A., and Poutiatine, M. (2010). Transformational learning for school leaders: Movement for social justice in school leaders' preparation. International Journal of Educational Leadership Preparation, 5(3).

[10] Drew, L. (2014). Embodied learning processes in activism. The Canadian Journal for the Study of Adult Education, 27(1), 83-101.

[11] Eddy, M. (2007). A balanced brain equals a balanced person: Somatic education. SPINS Newszine, 3(1),7-8.

[12] Ergas,O. (2013). "Two Mind-Altering Curriculums: Contemplation, Mindfulness, and the Educational Question Whether 'To Think or Not to Think?” Journal of Transformative Education, 11(4), 275-296.

[13] Farb,N., Daubenmier,J., Price,C.J., Gard, T., Barnaby Dunn,K., Klein, A.C., Paulus, M.P.,and Mehling, W. (2015). Interoception, contemplative practice, and health. Frontiers in Psychology, 6, 1-26.

[14] Fonow, M.M., Cook, J.A., Goldsand, R.S., and Burke-Miller, J.K. (2017a). Implications of Feldenkrais Method of Somatic Education to Enhance Mindfulness, Body Awareness and Empathic Leadership among College Students. Journal of Leadership Education. 15(3), 116-130.

[15] Fonow, M.M., Cook, J.A., Goldsand, R.S., and Burke-Miller, J.K. (2017b).Implications of Feldenkrais Method of Somatic Education for Training College Students to be Transformational Leaders. Journal of Education and Social Policy. 4(3), 149-158.

[16] Farmer,H.and Maister, L. (2017). Putting ourselves in another's skin: Using the plasticity of self-perception to enhance empathy and decrease prejudice. Social Justice Research, 30(4), 323-354.

[17] Glaser, B.G. and Strauss, A. (1967). The Discovery of Grounded Theory: Strategies for Qualitative Research. Chicago, IL: Aldine Publishing Co. 
An Integrative Approach to Developing Social Justice Leadership by Enhancing Body Awareness, Mindfulness and Transformational Styles of Interaction

[18] Glomb,T.M., Duffy, M.K., Bono, J.E.and Yang, T. (2011). Mindfulness at work. Research in Personnel and Human Resources Management, 30, 115-157.

[19] Heiden,M.Lyskov,E., Nakata,M., Sahlin,K., Sahlin,T., and Barnekow-Bergkvist, M. (2007).Evaluation of cognitive behavioural training and physical activity for patients with stress-related illnesses: A randomized controlled study. Journal of Rehabilitation Medicine, 39(5), 366-373.

[20] Johnson, Rae. (2018). Embodied Social Justice. New York: Routledge.

[21] Johnson, S.K., Frederick, J., Kaufman, M., and Mountjoy, B. (1999). A controlled investigation of bodywork in multiple sclerosis. The Journal of Alternative and Complementary Medicine, 5(3), 237-243.

[22] Jost,J.T., Nam,H.H., Amodio,D.M., and Van Bavel,J.J. (2014). Political neuroscience: The beginning of a beautiful friendship. Advances in Political Psychology, 35, 3-42.

[23] Kuepers, W.M. (2011). "Trans-+-form": Leaders and followership as an embodied, emotional and aesthetic practice for creative transformation in organisations. Leadership and Organisation Development Journal, 32(1), 20-40.

[24] Kuhnert,K.W., and Lewis,P. (1987). Transactional and transformative leadership: a constructive/ development tal analysis. The Academy of Management Review, 12(4), 648- 657.

[25] Ladkin,D. (2008). Leading beautifully: How mastery, congruence and purpose create the aesthetic of embodied leadership practice. The Leadership Quarterly, 19(1), 31-41.

[26] Magee, R.V. 2017. One field, different doors in: Contemplative higher education, transformative education and education for social justice. ICEA Journal, 1(1), 119-127.

[27] Malmgren-Olsson, E.B., Armelius, B.A., and Armelius, K. (2001). A comparative outcomes study of body awareness therapy, Feldenkrais, and conventional physiotherapy for patients with nonspecific musculoskeletal disorders: Changes in psychological symptoms, pain, and self-image. Physiotherapy Theory and Practice, 17(2), 77-95.

[28] Niemi, L., and Young, L. (2017). Who sees what as fair? Mapping individual differences in valuation of reciprocity, charity, and impartiality. Social Justice Research, 30(4), 438-449.

[29] Ohmann, A., Astrom, L., and Malmgren-Olsson, E.B. (2011). Feldenkrais therapy as group Awareness through Movement for chronic pain: A qualitative evaluation. Journal of Bodywork and Movement Therapies, 15(2), 153-161.

[30] Pinck, A.S. and Sonnentag, S. (2018). Leader mindfulness and employee well-being: The mediating role of transformational leadership. Mindfulness.(9), 884-896.

[31] Pitts-Taylor,V. (2016). The Brain's Body: Neuroscience and Corporeal Politics. Durham and London: Duke University Press.

[32] Reese, M. (2015). A Life in Movement: The Definitive Biography of Moshe Feldenkrais. San Rafael, CA: Reese Kress Somatics Press.

[33] Rockefeller,S.C. (2006). Meditation, social change, and undergraduate education.Teachers College Record. 108(9), 1775-1786.

[34] Sinclair, A. (2005). Body possibilities in leadership. Leadership, 1(4), 387-406.

[35] Verhaeghen, P. and Aikman, S.N. (2020). How the mindfulness manifold relates to the five moral foundations: Prejudice, and the awareness of privilege. Mindfulness. (11), 241-254.

[36] Vonderlin, R., Biermann, M., Bohus,M. and Yessko, L.L. (2020). Mindfulness-based programs in the workplace: Aa meta-analysis of randomized control trials. Mindfulness. (11), 1579-1598.

Citation: Mary Margaret Fonow, et al. "An Integrative Approach to Developing Social Justice Leadership by Enhancing Body Awareness, Mindfulness and Transformational Styles of Interaction". International Journal of Humanities Social Sciences and Education (IJHSSE), vol. 7, no. 9, 2020, pp. 32-43. doi: https://doi.org/lo.20 431/2349-0381.0709003.

Copyright: (C) 2020 Authors. This is an open-access article distributed under the terms of the Creative Commons Attribution License, which permits unrestricted use, distribution, and reproduction in any medium, provided the original author and source are credited. 